\title{
Generalized Family of Group Chain Sampling Plans Using Minimum Angle Method (MAM)
}

\author{
Mohd Azri Pawan Teh ${ }^{1, *}$, Nazrina Aziz ${ }^{1,2}$, Zakiyah Zain ${ }^{1,2}$ \\ ${ }^{1}$ Department of Mathematics \& Statistics, School of Quantitative Sciences, Universiti Utara Malaysia, 06010 UUM Sintok, \\ Kedah, Malaysia \\ ${ }^{2}$ Institute of Strategic Industrial Decision Modelling (ISIDM), Universiti Utara Malaysia, 06010 UUM Sintok, Kedah, Malaysia
}

Received September 6, 2021; Revised November 17, 2021; Accepted December 21, 2021

\section{Cite This Paper in the following Citation Styles}

(a): [1] Mohd Azri Pawan Teh, Nazrina Aziz, Zakiyah Zain, "Generalized Family of Group Chain Sampling Plans Using Minimum Angle Method (MAM)," Mathematics and Statistics, Vol. 10, No. 2, pp. 314 - 319, 2022. DOI: 10.13189/ms.2022.100205.

(b): Mohd Azri Pawan Teh, Nazrina Aziz, Zakiyah Zain (2022). Generalized Family of Group Chain Sampling Plans Using Minimum Angle Method (MAM). Mathematics and Statistics, 10(2), 314 - 319. DOI: 10.13189/ms.2022.100205.

Copyright $\odot 2022$ by authors, all rights reserved. Authors agree that this article remains permanently open access under the terms of the Creative Commons Attribution License 4.0 International License

\begin{abstract}
This research develops a generalized family of group chain sampling plans using the minimum angle method (MAM). The MAM is a method whereby both the producer's and consumer's risks are considered when designing the sampling plans. There are three sampling plans nested under the family of group chain acceptance sampling which are group chain sampling plans (GChSP-1), new two-sided group chain sampling plans (NTSGChSP-1), and two-sided group chain sampling plans (TSGChSP-1). The methodology applied is random values of the fraction defectives for both producer and consumer, and the optimal number of groups, $g$ is obtained using the Scilab software. The findings reveal that some of the design parameters manage to obtain the $g$ corresponding to the smallest angle, $\theta$ and some of the values fail to get the $g$. The $g$ obtained in this research guarantees that the producer and the consumer are protected at most $10 \%$ from having defective items.
\end{abstract}

Keywords Consumer's Risk, Generalized Family of Group Chain Sampling Plans, Minimum Angle Method, Producer's Risk

\section{Introduction}

Acceptance sampling is among the oldest techniques in statistical quality control, approaching its century-old of age. It was reportedly first introduced in 1924 at Western
Electric's Bell Telephone Laboratory [1]. This was the birthplace of the fathers of acceptance sampling: Dodge, Shewhart, Juran, and Romig. They introduced the important concepts in the field such as operating characteristic (OC) curve, probability of lot acceptance, consumer's risk (CR), producer's risk (PR), single sampling plans (SSP), and double sampling plans (DSP).

Two classifications are used in acceptance sampling, which are attribute plan and variable plan $[2,3,4]$. The attribute plan takes into account the quality characteristics of an item such as pass or fail and defective or non-defective. The variable plan considers the quality characteristics that are measured on a continuous scale such as volume. It is to be noted that this paper only highlights the attribute plans.

In acceptance sampling, the decision of whether or not to accept a lot is solely determined by the inspection result of its random sample [5]. For instance, if the number of defectives, $d$ does not exceed the acceptance number, $a$, the entire lot is accepted. Meanwhile, if $d>a$, the entire lot will be disposed as reject. Different sampling plans have different acceptance criteria or rejection criteria, and the difference in these criteria makes each sampling plan unique.

Reliability and lifetime of an item play a big part in deciding the value of fraction defective [6,7]. Reliability is defined as the statistical estimation of the ability of the item to function under specified design limits, while lifetime stands for the statistical estimation of how long the item will last $[8,9,10]$. Usually, an item of high quality has a 
very long lifetime and it can cause time-wasting if an inspector has to wait until the item fails. To solve this issue, the test time is often terminated at a certain value; this is termed time as a truncated life test.

Based on the fraction defective, many researchers developed acceptance sampling plans using different distributions [11, 12, 13] such as exponential [14], log-logistic [15], Pareto of the 2nd kind [16], Rayleigh [17], inverse Rayleigh [18] and Gamma [19] distributions. Apart from the lifetime distributions, the fraction defective of an item can be generalized where the values for the fraction defective can be set at any value [1]. The generalized values of the fraction defective are regarded as a more favourable approach as there is no need to specify any lifetime distribution. Also, it can cater to most of the fraction defectives of a product. Therefore, this research develops the generalized family of group chain sampling plans using the minimum angle method (MAM) where the fraction defective values are set from 0.001 to 0.05 with 0.001 increments.

The MAM is a method whereby both producer's and consumer's risks are minimized in developing the acceptance sampling plan. This is accomplished by minimizing the angle $\theta$ corresponding to points $A\left(p_{1}, 1-\alpha\right)$ and $B\left(p_{2}, \beta\right)$, as depicted in Figure 1, where $p_{1}$ is the fraction defective at the acceptable quality level, AQL, $\alpha$ is the producer's risk, $p_{2}$ is the fraction defective at the limiting quality level, LQL and $\beta$ is the consumer's risk. It is to be noted that $L\left(p_{1}\right)$ and $L\left(p_{2}\right)$ represent the probability of lot acceptance associated with the AQL and LQL respectively.

There are two advantages when applying the minimum angle method. The first advantage is that it minimizes both CR and PR, concurrently. To date, researchers only take into account the CR when developing the family of GChSP, completely disregarding the PR. With the recent development of family of GChSP, customers are always on the winning side since their risks are kept as low as possible, but producers, on the other hand, are rather neglected as the plan does not consider their risk at all. The above situation is unfair to the producers; their risk should also be taken into consideration when developing the family of GChSP. The second advantage is that the calculated angle using the proposed MAM, approaches that of the ideal OC curve. This refers to the zero angle as depicted by the AC chord in Figure 1. Theoretically, this ideal OC curve can only be achieved when $100 \%$ inspection is conducted, which is impractical since it is too time-consuming and expensive. Therefore, by applying the proposed method, the smallest angle produced is believed to approach the value of angle created by the ideal OC curve; this enables more accurate lot sentencing similar to that of $100 \%$ inspection but at a minimal cost of using a sample.

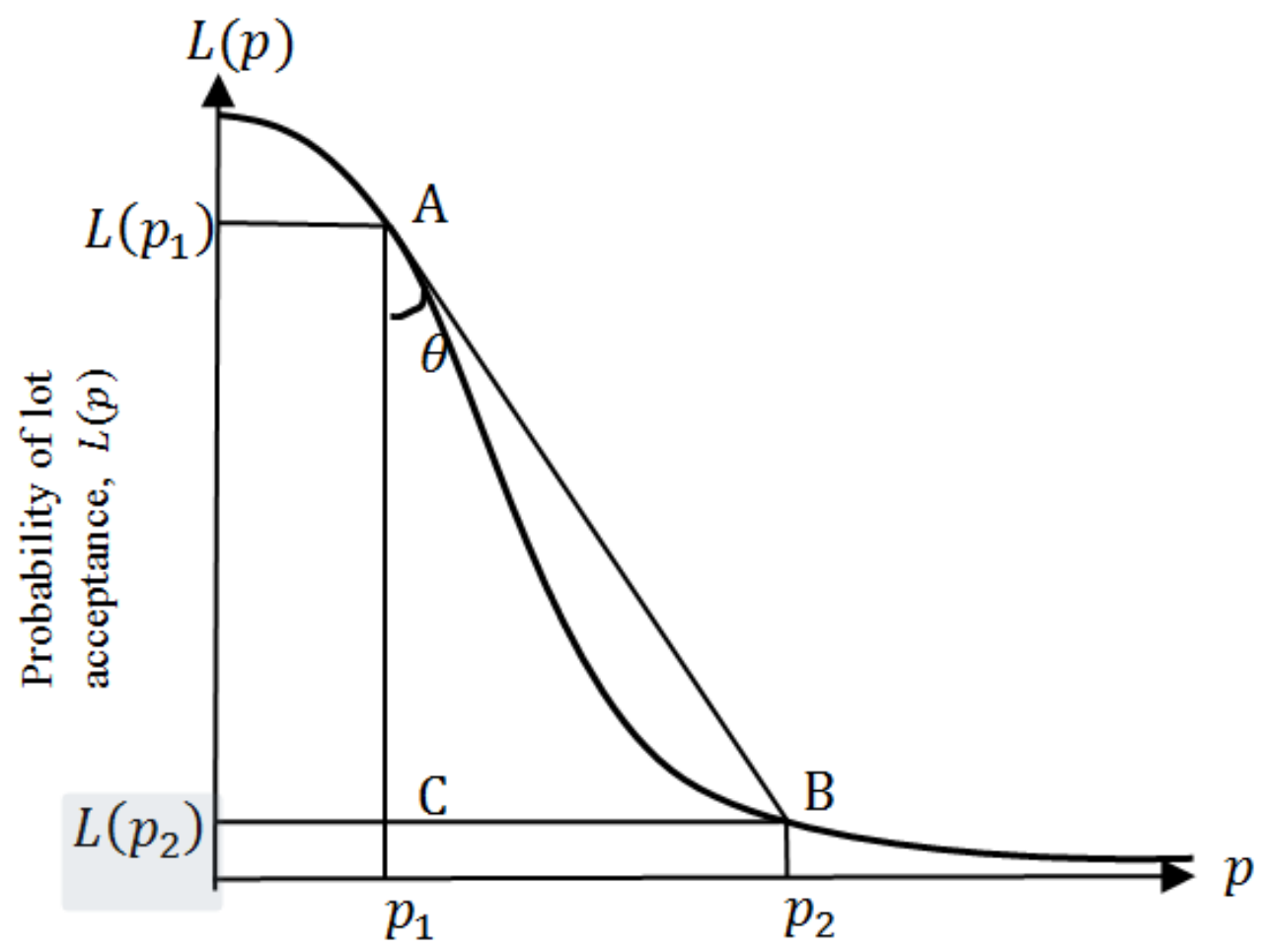

Fraction

Figure 1. The minimum angle method (MAM) 


\section{Methodology}

\subsection{Glossary of Symbols}

$\begin{array}{ll}a & : \text { Acceptance number } \\ d & : \text { Number of defectives } \\ g & : \text { Optimal number of groups } \\ i & : \text { Number of preceding lots } \\ j & : \text { Number of succeeding lots } \\ \mathrm{AQL} & : \text { Acceptable quality level } \\ \mathrm{LQL} & : \text { Limiting quality level } \\ p_{1} & : \text { Fraction defective at the AQL } \\ p_{2} & : \text { Fraction defective at the LQL } \\ r & : \text { Number of items } \\ t_{0} & : \text { Test termination time } \\ L\left(p_{1}\right) & : \text { Probability of lot acceptance at the AQL } \\ L\left(p_{2}\right) & : \text { Probability of lot acceptance at the LQL } \\ \theta & : \text { Smallest angle } \\ \alpha & : \text { Producer's risk } \\ \beta & : \text { Consumer's risk }\end{array}$

\subsection{Design Parameters}

The design parameters for the generalized family of GChSP are given in Table 1 as Schilling and Neubauer [20] suggest that the generalized values for the fraction defective should be small.

Producer's risk, $\alpha$ represents the chances of rejecting a good lot, while consumer's risk, $\beta$ represents the chances of accepting a bad lot [21]. In essence, these two risks are Type I and Type II errors respectively, which are inevitable in statistical inference. In acceptance sampling, since the inspection is conducted on a random sample, there is always a possibility of making wrong decisions. In this study, the values of the two risks are set to be below 0.10 , indicating that both producer and consumer will have less than $10 \%$ chances of rejecting a good lot and accepting a bad lot.

Specified constant, $a$ is written as $t=a \mu_{0}$, where $t$ is the test termination time and $u_{0}$ is the specified mean life. The specified constant, $a$ provides two scenarios regarding the inspection time. The first scenario is for $a<1$, which means the inspection time is terminated before the item reaches its minimum lifetime. For instance, if $a=0.5$ and $\mu_{0}=1000$ hours, it indicates that the inspection time is stopped at 500 hours even though the item has not reached its minimum lifetime.

The second scenario is for $a \geq 1$, which indicates the inspection time is set to be terminated after the item achieves its minimum lifetime. For example, if $a=1.5$ and $\mu_{0}=1000$ hours, it means that the inspection is ended at 1500 hours, where the item has passed its actual lifetime. In this study, both scenarios ( $a<1$ and $a \geq 1$ ) are investigated in order to avail a better picture for the inspectors regarding the effect of $a$ on the sample size (in relation to $g$, for the family of GChSP.

The number of preceding lots, $i$ is the total number of previous lots considered when sentencing (accept or reject) the current lot under inspection. All the developed plans include $i$ as a design parameter. It plays an important role since the $i$ influences the decision of acceptance or rejection. For instance, in the GChSP-1, if one defective is detected in the current sample, and zero in the previous $i$ samples (lots), then the current lot is accepted. Conversely, the current lot is to be rejected if its sample contains one defective and the previous $i$ samples recorded at least one defective (making the combined total of 2 or more defectives).

Meanwhile, the number of succeeding lots, $j$ is the number of subsequent lots considered when sentencing the lot. Unlike the $i$, TSCGChSP-1, NTSGChSP-1 and TSGChSP-1 have $j$ as the design parameters. Essentially, it functions like the $i$, in determining the lot acceptance or rejection. For example, in the TSCGChSP-1, if the current sample has one defective and zero defective found in both the $i$ and $j$ lots, then accept the current lot. However, if the current sample has one defective and $j$ lot has at least one defective too, then reject the current lot. It is to be noted that these plans operate under the premise of allowing a maximum combined defective of not more than one, to assure quality and safeguard both producers and consumers.

Table 1. Design parameters for the generalized family of GChSP

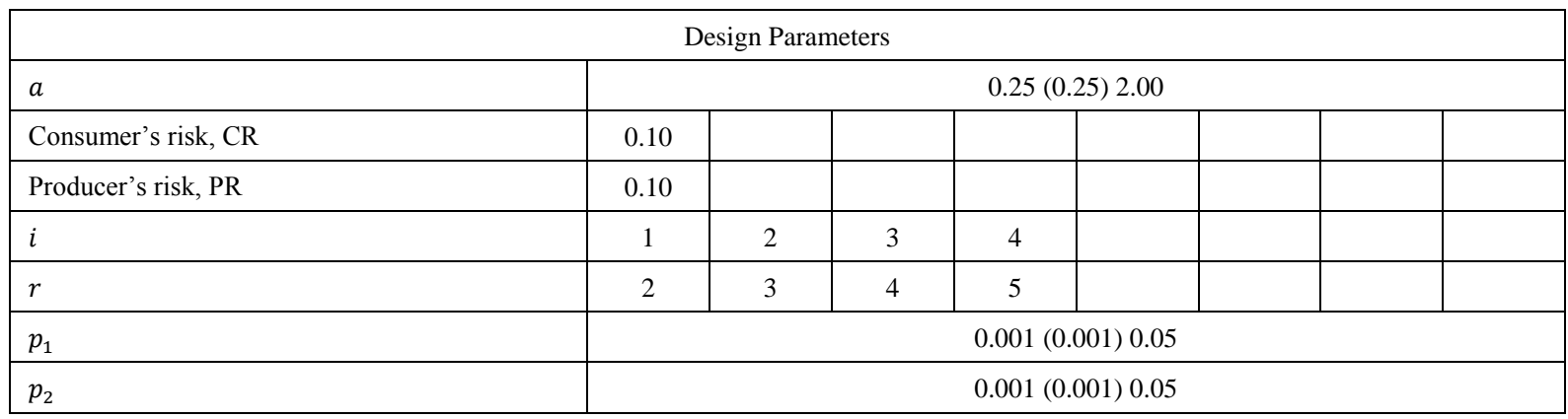


There are two cases when deciding the values of $i$ and $j$, which are $i=j$ and $i \neq j$. For the first case, if the values of $i=3$, then $j=3$ too. For the second case, if the value of $i=3$, then $j$ cannot be 3 . This study only caters to the first case, in which it is assumed that $i=j$. The assumption is important since it eases the derivation of $L(p)$. This is useful in examining how the $i$ and $j$ affect the $g$. The second case is not considered in this study other researchers might be interested to study all the three sampling plans when $i \neq j$.

It is to be recalled that items are inspected simultaneously in the group chain. Thus, the sample size is made up of $g$ multiples of $r$ items $(n=g r)$. In other words, $r$ is defined as the number of items that are placed into a particular group - all the sampling plans in this study employ $r$ as the design parameter. The value of $r$ must be greater than or equal to 2 and it cannot take 1 as its value. If $r=1$, then the proposed sampling plans (for instance GChSP-1) become the ordinary sampling plans (in this case, ChSP-1). In this study, $r$ is set to have a range of 2 to 5 in examining the effect of $r$ on $g$.

\subsection{Operating Procedures}

This section outlines the operating procedures for the group chain sampling plans (GChSP-1), new two-sided group chain sampling plans (NTSGChSP-1), and two-sided group chain sampling plans (TSGChSP-1).

Operating procedure for GChSP-1:

Step 1: Obtain $g$ by using the MAM.

Step 2: Accept the lot when $d=0$.

Step 3: Accept it when $d=1$ and $d_{i}=0$.

If not, reject it.

Step 4: Reject it when $d>1$.

\section{Operating procedure for NTSGChSP-1}

Step 1: Obtain $g$ by using the MAM.

Step 2: Accept the lot when $d=0$ given that $d_{i}+$ $d_{j} \leq 1$.

Step 3: Accept it when $d=1$ given that $d_{i}=0$ and $d_{j}=0$. If not, reject it.

Step 4: Reject it when $d>1$.

Operating procedure for TSGChSP-1

Step 1: Obtain $g$ by using the MAM.

Step 2: Accept the lot when $d=0$ given that:

$d_{i}=0$ and $d_{j}=0$.

$d_{i}=0$ and $d_{j}=1$.
If not, reject it.

$$
d_{i}=1 \text { and } d_{j}=0 .
$$

Step 3: Reject it when $d \geq 1$.

\subsection{Probability of Lot Acceptance, $L(p)$}

The $L(p)$ for the three sampling plans is derived based on their respective operating procedures. Upon simplification, the $L(p)$ for the three sampling plans is given by:

$$
\begin{gathered}
L(p)_{G C h S P-1}=(1-p)^{g r}\left[\frac{(1-p)^{g r i} \operatorname{grp}}{1-p}+1\right] \\
L(p)_{N T S G C h S P-1}=(1-p)^{g r(2 i+1)}\left[\frac{(2 i+1)(g r p)}{1-p}+1\right] \\
L(p)_{T S G C h S P-1}=(1-p)^{g r(2 i+1)}\left[\frac{2 g r i p}{1-p}+1\right]
\end{gathered}
$$

The $g$ is obtained when the following conditions are fulfilled:

$$
L\left(p_{1}\right) \geq 1-\alpha
$$

and

$$
L\left(p_{2}\right) \leq \beta,
$$

where $\alpha$ and $\beta$ are set to be less than 0.10 .

The $\theta$ is then calculated using:

$$
\tan \theta=\frac{p_{2}-p_{1}}{L\left(p_{1}\right)-L\left(p_{2}\right)} .
$$

\section{Results and Discussion}

Table 2 shows the $g$ values for the generalized sampling plans developed. It is to be observed that only some of the proposed design parameters fulfill the producer's and consumer's risks conditions of less than 0.10 . The GChSP- 1 only has 3 outcomes, NTSGChSP-1 has 13 outcomes and TSGhCP-1 only has 2 outcomes. For instance, $g$ for the GChSP-1 is 155 when the set values of the parameters are $\left(p_{1}, p_{2}, i, r\right)=(0.001,0.009,1,2)$. The 155 groups are obtained as it managed to record 0.099789 for the $\alpha$ and 0.071006 for the $\beta$. The corresponding $\theta$ for the 155 is given by the last column $0.552761^{\circ}$. The 155 groups suggest that the producer and the consumer are protected from having more than $10 \%$ wrong decisions. Simply stated, in 100 accepted lots, there will be less than 10 bad lots ( $<10 \%$ consumer's risk). Similarly, if 100 lots were rejected, chances are more than 90 of them were really bad lots, and only less than 10 good lots were rejected $(<10 \%$ producer's risk). 
Table 2. The $g$ for the generalized family of group chain sampling plans

\begin{tabular}{|c|c|c|c|c|c|c|c|}
\hline$p_{1}$ & $p_{2}$ & $i$ & $r$ & $g$ & $\alpha$ & $\beta$ & $\theta$ \\
\hline \multicolumn{8}{|c|}{ GChSP-1 } \\
\hline 0.001 & 0.009 & 1 & 2 & 155 & 0.099789 & 0.071006 & $0.552761^{o}$ \\
\hline 0.001 & 0.01 & 1 & 2 & 155 & 0.099789 & 0.050511 & $0.606853^{\circ}$ \\
\hline 0.001 & 0.01 & 2 & 3 & 81 & 0.098528 & 0.088581 & $0.63433^{\circ}$ \\
\hline \multicolumn{8}{|c|}{ NTSGChSP-1 } \\
\hline 0.001 & 0.004 & 2 & 3 & 123 & 0.059498 & 0.09951 & $0.204386^{\circ}$ \\
\hline 0.001 & 0.004 & 3 & 4 & 70 & 0.034113 & 0.099645 & $0.198428^{\circ}$ \\
\hline 0.001 & 0.004 & 4 & 5 & 46 & 0.027829 & 0.092756 & $0.195456^{\circ}$ \\
\hline 0.001 & 0.005 & 1 & 2 & 225 & 0.044442 & 0.085501 & $0.26341^{o}$ \\
\hline 0.001 & 0.006 & 1 & 2 & 202 & 0.013862 & 0.064285 & $0.310761^{o}$ \\
\hline 0.002 & 0.007 & 3 & 4 & 40 & 0.099067 & 0.099238 & $0.357337^{\circ}$ \\
\hline 0.002 & 0.007 & 4 & 5 & 26 & 0.089652 & 0.096172 & $0.351859^{\circ}$ \\
\hline 0.002 & 0.008 & 2 & 3 & 62 & 0.062926 & 0.096146 & $0.408797^{\circ}$ \\
\hline 0.002 & 0.008 & 3 & 4 & 35 & 0.034014 & 0.099102 & $0.396558^{\circ}$ \\
\hline 0.002 & 0.008 & 4 & 5 & 23 & 0.027732 & 0.09223 & $0.39063^{\circ}$ \\
\hline 0.002 & 0.009 & 1 & 2 & 120 & 0.065535 & 0.098324 & $0.479657^{\circ}$ \\
\hline 0.002 & 0.009 & 2 & 3 & 55 & 0.01507 & 0.096714 & $0.451537^{\circ}$ \\
\hline 0.002 & 0.01 & 1 & 2 & 112 & 0.042941 & 0.086295 & $0.526381^{o}$ \\
\hline \multicolumn{8}{|c|}{ TSGChSP-1 } \\
\hline 0.001 & 0.01 & 3 & 4 & 14 & 0.097209 & 0.085477 & $0.630898^{\circ}$ \\
\hline 0.001 & 0.01 & 4 & 5 & 9 & 0.092855 & 0.079146 & $0.622757^{\circ}$ \\
\hline
\end{tabular}

\section{Conclusions}

This study explored the generalized family of group chain sampling plan particularly the GChSP-1, NTSGChSP-1 and TSGChSP-1. The generalized sampling plans were proposed as the plans did not take into account any lifetime distribution for the fraction defective values; instead, it applied random values of the fraction defective, as given in Table 1. The findings revealed that some of the random values of the fraction defectives yielded the $g$ while the rest of the random fraction defective values failed to obtain the $g$. The main reason for failure in obtaining the $g$ was the $L(p)$ for both consumer's and producer's risks were higher than 0.10 , whereas this study has limited that the $L(p)$ should be less than 0.10 . The risk values guarantee that both parties, the producer and consumer are protected at least $90 \%$ of the time. Practically, these plans should offer better alternatives to industrial practitioners in any sectors involving product life test.

\section{Acknowledgments}

This research was supported by Ministry of Higher
Education (MoHE) of Malaysia through Fundamental Research Grant Scheme (FRGS/1/2018/STG06/UUM/02/ 6).

\section{REFERENCES}

[1] Mughal, A. R., Zain, Z., \& Aziz, N. (2015). New two-sided complete group chain sampling plan for Pareto distribution of the 2nd kind. International Journal of Applied Engineering Research, 10 (12), 31855-31860.

[2] Allen, T. T. (2006). Introduction to engineering statistics and six sigma: statistical quality control and design of experiments and systems. London: Springer.

[3] Montgomery, D.C. Introduction to Statistical Quality Control. John Wiley \& Sons. 2019

[4] Jamaludin, A. F., Zain, Z., \& Aziz, N. (2016). A modified group chain sampling plans for lifetimes following a Rayleigh distribution. Global Journal of Pure and Applied Mathematics, 12 (5), 3941-3947.

[5] Stephens, K. S. (2001). The handbook of applied acceptance sampling: plans, procedures, and principles. Wisconsin: ASQ Quality Press. 
[6] Wood, A. (1996). Predicting software reliability, IEEE Transactions on Software Engineering, 29(11), 69-77.

[7] ReliaSoft Corporation. (2015, May 22). Life Data Analysis Reference. Retrieved from http://www.ReliaSoft.com

[8] Montgomery, D. C., \& Runger, G. C. (2003). Applied statistics and probability for engineer (3rd ed.). New York: John Wiley \& Sons, Inc.

[9] Pham, H. (2006). Springer series in reliability engineering: system software reliability. Springer.

[10] O’Connor, A. N., Modarres, M., \& Mosleh, A. (2016) Probability distributions used in reliability engineering. Maryland: Center for Reliability Engineering.

[11] Dodge, H. F. (1955). Chain sampling inspection plan. Industry Quality Control, 11(4), 10-13.

[12] Gupta, S. S., \& Groll, P. A. (1961). Gamma distribution in acceptance sampling based on life tests. Journal of the American Statistical Association, 56, 942-970.

[13] Gupta, S. S. (1962). Life test sampling plans for normal and lognormal distributions. Technometrics, 4(2), 151-175.

[14] Epstein, B. (1954). Truncated life tests in the exponential case. The Annals of Mathematical Statistics, 25(3), 555-564.
[15] Kantam, R. R. L., Rosaiah, K., \& Rao, G. S. (2001). Acceptance sampling based on life tests: log-logistic model. Journal of Applied Statistics, 28(1), 121-128.

[16] Baklizi, A. (2003). Acceptance sampling based on truncated life tests in the Pareto distribution of the $2^{\text {nd }}$ kind. Advances and Applications in Statistics, 3(1), 33-48.

[17] Tsai, T. R., \& Wu, S. J. (2006). Acceptance sampling based on truncated life tests for generalized Rayleigh distribution. Journal of Applied Statistics, 33(6), 595-600.

[18] Teh, M. A. P., Aziz, N., \& Zain, Z. (2016). Group chain sampling plans based on truncated life test for inverse Rayleigh distribution. Research Journal of Applied Sciences, 11(11), 1432-1435.

[19] Teh, M. A. P., Aziz, N., \& Zain, Z. (2019). Time truncated group chain sampling plans for gamma Distribution. International Journal of Innovative Technology and Exploring Engineering, 8(5S), 62-65.

[20] Schilling, E. G., \& Neubauer, D. V. (2017). Acceptance sampling in quality control ( $3^{\text {rd }}$ edition). CRC Press.

[21] Aziz, N., Hasim, Z. and Zain, Z. Two -Sided Group Chain Sampling Plans Based on Truncated Life Test for Generalized Exponential Distribution. Mathematics and Statistics, Volume 9, Number 4, PP: 439 - 444. 2021. DOI: 10.13189/ms.2021.090404 . 